\title{
Unveiling the Link between the Third Law of Comminution and the Grinding Kinetics Behaviour of Several Ores
}

\author{
Victor Ciribeni ${ }^{1}{ }^{\complement}$, Juan M. Menéndez-Aguado ${ }^{2, *}$,, Regina Bertero ${ }^{1}$, Andrea Tello ${ }^{1}$, Enzo Avellá ${ }^{1}$, Matías Paez ${ }^{1}$ \\ and Alfredo L. Coello-Velázquez ${ }^{3}$ \\ 1 Instituto de Investigaciones Mineras, Universidad Nacional de San Juan, San Juan 5400, Argentina; \\ ciribeni@unsj.edu.ar (V.C.); reginabertero@gmail.com (R.B.); act8383@gmail.com (A.T.); \\ enavella.91@gmail.com (E.A.); matias.p043@gmail.com (M.P.) \\ 2 Escuela Politécnica de Mieres, University of Oviedo, Gonzalo Gutiérrez Quirós, 33600 Mieres, Spain \\ 3 CETAM, Universidad de Moa Dr. Antonio Núñez Jiménez, Moa 83300, Cuba; acoello@ismm.edu.cu \\ * Correspondence: maguado@uniovi.es; Tel.: +34-985458033
}

check for

updates

Citation: Ciribeni, V.;

Menéndez-Aguado, J.M.; Bertero, R.;

Tello, A.; Avellá, E.; Paez, M.;

Coello-Velázquez, A.L. Unveiling the

Link between the Third Law of

Comminution and the Grinding

Kinetics Behaviour of Several Ores.

Metals 2021, 11, 1079. https://

doi.org/10.3390/met11071079

Academic Editor: Anna H. Kaksonen

Received: 9 June 2021

Accepted: 4 July 2021

Published: 5 July 2021

Publisher's Note: MDPI stays neutral with regard to jurisdictional claims in published maps and institutional affiliations.

Copyright: (c) 2021 by the authors. Licensee MDPI, Basel, Switzerland. This article is an open access article distributed under the terms and conditions of the Creative Commons Attribution (CC BY) license (https:/ / creativecommons.org/licenses/by/ $4.0 /)$.

\begin{abstract}
As a continuation of a previous research work carried out to estimate the Bond work index $\left(w_{i}\right)$ by using a simulator based on the cumulative kinetic model (CKM), a deeper analysis was carried out to determine the link between the kinetic and energy parameters in the case of metalliferous and non-metallic ore samples. The results evidenced a relationship between the CKM kinetic parameter $k$ and the grindability index $g b p$; and also with the $w_{i}$, obtained following the standard procedure. An excellent correlation was obtained in both cases, posing the definition of alternative work index estimation tests with the advantages of more straightforward and quicker laboratory procedures.
\end{abstract}

Keywords: grinding kinetics; grindability; comminution; bond work index

\section{Introduction}

The importance of work index determinations in mineral ores comminution operations is without any doubt. The methodology proposed by F.C. Bond [1] is widely used in grinding equipment design and calculations. The crucial point is that it was developed on an enormous data quantity, both at laboratory and industrial scales, yielding sound and reliable results. This fact provided Bond's methodologies with great prestige from its inception and, despite many attempts to develop a technique to replace it over time, it established itself as an essential tool for design and sizing the reduction stages of hundreds of metallurgical plants around the world.

However, the Bond proposal has some shortcomings, pointed out by Gutierrez and Sepulveda [2], Aksani and Sömmez [3] and Menendez Aguado et al. [4], which are summarized below:

- Availability of the standard mill

- Availability of a minimum sample of $10 \mathrm{~kg}$

- Excessive duration of the procedure (in case of some ores)

- Lack of detailed procedure definition (there is no ASTM or ISO specific standard)

These shortcomings have fostered the proposal of alternative grindability characterization procedures. Thus, Lvov and Chitalov [3] performed an in-depth review of several alternative methodologies. Recently, Josefin and Doll [4] proposed an alternative methodology to obtain $w_{i}$ at a different closure size $\left(P_{100}\right)$ than the one tested, and Nikolić and Trumić [5] proposed an alternative procedure when the feed top size $\left(F_{100}\right)$ is much lower than $3.35 \mathrm{~mm}$, the top size referenced in the Bond standard methodology (BSM). Moreover, estimating the work index variability from the variability of the geomechanical parameters is the central idea of several alternative procedures, as recently proposed by Park and Kim [6]; this mine-to-mill approach needs further development, but opens a promising way related to mine digitalization strategies for process optimization. Currently, new tools 
are being developed to estimate $w_{i}$, some of which stand out for the reuse of equipment applying modern technologies, simplifying methodologies or applying mathematical models, as it is the case of the following authors:

- Aksani et al. [7] proposed a methodology to obtain the work index by simulation using the CKM and showed results for six different ores, reporting deviations less than $4 \%$.

- Menéndez Aguado et al. [8] showed an alternative methodology based on a nonstandard mill, reporting a mean square error of less than $3 \%$.

- Ahmadi et al. [9] presented a methodology with an industrial-scale validation; deviations reported in this case were less than $7 \%$.

- Mwanga et al. $[10,11]$ developed an alternative small sample methodology (300 g) with a geometallurgical approach, reporting mean square error less than $5 \%$.

- Heiskari et al. [12] also presented an alternative methodology using a small sample quantity in a Mergan mill, as an evolution of the former proposal of Niiti [13]. The deviation values reported in this case were less than $4 \%$.

Moreover, Ciribeni et al. [14] proposed a simplified technique to determine the CKM kinetic grinding parameters in order to simulate the Bond test and to validate it by contrasting the results of Au and $\mathrm{Ag}$ metalliferous ore samples from various deposits in the Argentine Patagonia. At present, the application of mathematical models to simulate grinding has proven to be a helpful tool for determining the work index, not only in the abovementioned case of Aksani et al. [7], but also in previous work from Lewis et al. [15] and more recently Silva et al. [16]. However, only some authors present alternatives that solve the difficulties of Bond's procedure. This method allows testing with a small sample, especially when looking to obtain the work rate of drill core samples, limiting the sample size to less than a pair of kilograms. This is usually the case of practical geometallurgy, which provides data for the economic and technical evaluation of mineral exploitation and the metallurgical plant, and seeks to predict the mineral behaviour in the metallurgical processes.

The simulator developed by Ciribeni et al. [14] allowed the estimation $w_{i}$ from the CKM kinetic parameters with a good approximation. Deniz [17] studied the relationship among the Bond standard test parameters and the kinetic parameters following the wellknown Austin methodology [18], suggesting several relationships between the grindability index $g b p$ and the set of kinetic data. However, this work was carried out only on one ore, and the practical advantage of this solution is not convenient, given that the determination of Austin parameters can involve even more laboratory work than in the test defined by the BSM in the case of ball mills. Moreover, several papers have been published studying the deviations from the linear kinetic approach $[19,20]$. However, the CKM procedure provides a quick parameter determination.

Hence, the objective of this research was to study the relationship between the CKM kinetic parameters and the Bond ball mill standard test parameters $\left(g b p, w_{i}\right)$ to propose alternative methodologies of work index estimation with practical advantages. The main hypothesis is that, as suggested by Deniz [17], there can be found a relationship between the CKM kinetic parameter $k$ and the power consumption parameters in the BSM, such as $g b p$ and $w_{i}$.

\section{Materials and Methods}

\subsection{The Cumulative Kinetic Model}

The cumulative kinetic model is the simple solution defined by Laplante [21], for the equation proposed by Loveday [22] as a first-order kinetic equation. The particle breakage rate in a given size interval is proportional to the mass present in this interval. The kinetic parameter $k$ is defined by the disappearance rate of oversize particles for a given size class (for both batch or continuous grinding-assuming a plug flow regime in the latter one) and can be described with the CKM model as expressed in Equation (1).

$$
W_{(x, t)}=W_{(x, 0)} \exp (-k \cdot t)
$$


wherein:

$W(x, t)=$ cumulative percentage of oversize of size class $x$ at time $t$.

$W(x, 0)=$ cumulative percentage of oversize of size class $x$ in the fresh feed.

$k=$ breakage rate constant $\left(\mathrm{min}^{-1}\right)$

$t=$ time, $(\mathrm{min})$

The equation that describes the relationship between the breakage rate and the particle size is shown in Equation (2):

$$
k=C \cdot x^{n}
$$

wherein $C$ and $n$ are constants, dependent on the characteristics of the ore and the mill, as described by Ersayin et al. [23]. $C$ and $n$ can be determined experimentally and once known the feed particle size distribution (PSD) the product PSD can be calculated by means of Equation (3).

$$
W_{(x, t)}=W_{(x, 0)}\left(\exp \left(-C \cdot x^{n} \cdot t\right)\right)
$$

\subsection{Kinetic Parameters Determination}

Kinetic parameter $k$ is determined with a small sample in a laboratory mill, as described in [14]. In this case, the standard mill designed by Bond is used to avoid introducing this uncertainty factor when simulating the Bond standard test.

With the same amount of feed from the Bond test $\left(700 \mathrm{~cm}^{3}\right)$, successive grinding runs are carried out at pre-established time intervals. Once finished each run, a representative sample of the mineral load is taken, and the product PSD is obtained; the sample is returned to the mill, recomposing the load and allowing the performance of the subsequent grinding run.

To simplify this test, the simplified methodology (SIM) presented in [14] proved that a single grinding run could be made to determine the kinetic parameter $k$, saving time and avoiding excessive manipulation of the sample. The $k$ value is determined for different monosizes, making the linear regression of the cumulative retained for the final milling time, using Equation (4):

$$
\operatorname{Ln}\left(W_{(x, t)}\right)-\operatorname{Ln}\left(W_{(x, 0)}\right)=k t
$$

\subsection{Experimental Procedure}

\subsubsection{Sample Preparation}

For this work, samples from three metalliferous ores from Argentine Patagonia were selected and prepared according to the conventional preparation scheme used to prepare the feed in a Bond's ball mill standard test (Figure 1). In each case, the sample amount prepared was enough to carry out the SIM tests to obtain the kinetic parameters $k$ [14] and also to obtain the BSM work index [1], which will be used for validation purposes.

PSD were obtained in a Ro-Tap sieve with sieves $203 \mathrm{~mm}$ in diameter (ASTM certified). Sampling was carried out in a Sieving Riffler Quantachrome eight sector rotary sampler. 


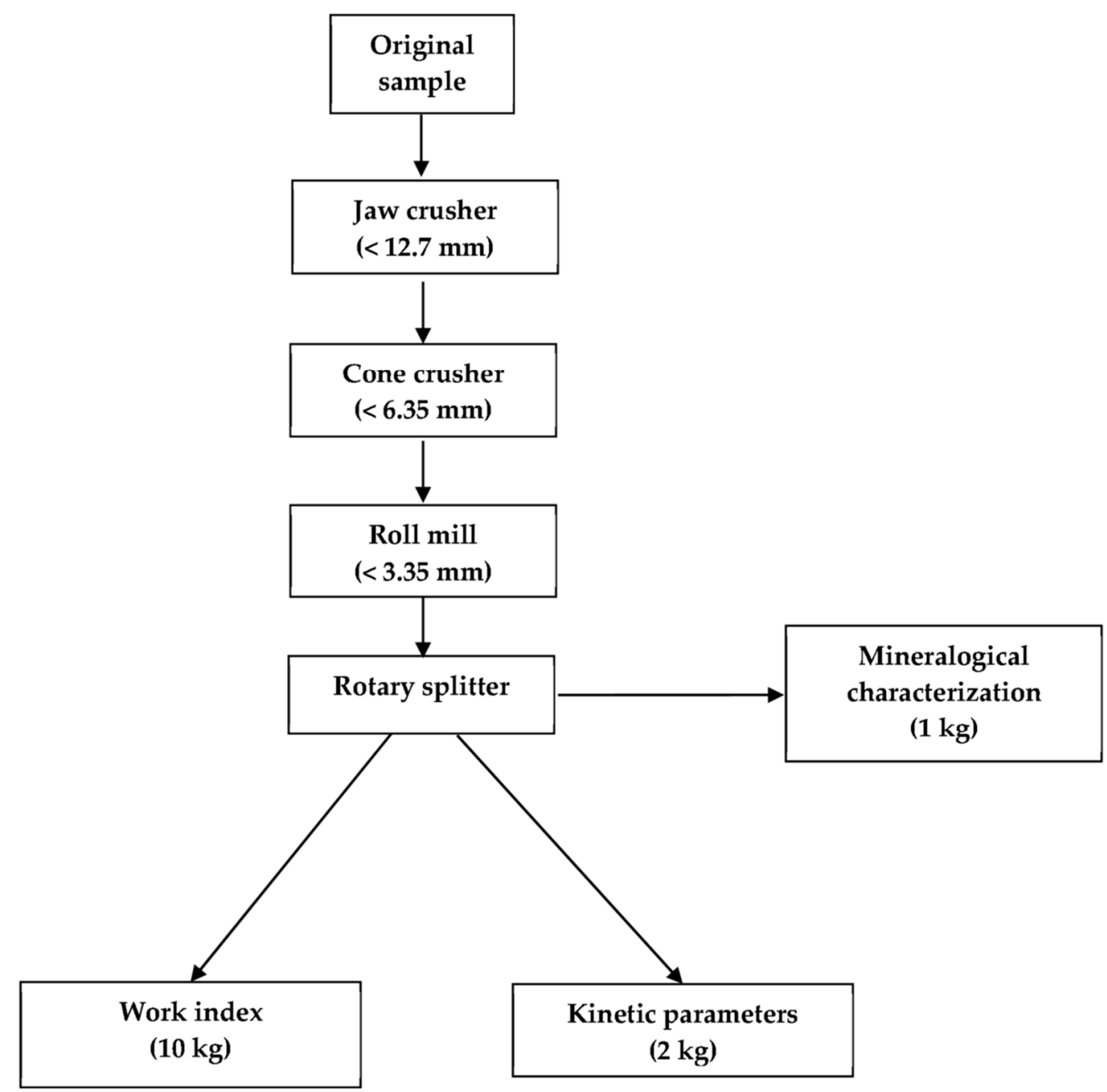

Figure 1. Samples preparation flowsheet.

\subsubsection{Sample Characterization}

To perform this study, data from Ciribeni et al. [14] were used. However, some additional ores were considered in this research and are included below.

The new samples came from metalliferous deposits $(\mathrm{Au}, \mathrm{Ag})$ from the metallogenetic province "Macizo del Deseado" (Argentine Patagonia):

- Low sulphidation (LS) ore: several samples were taken from this ore, which comes from a low sulphidation hydrothermal deposit, formed mainly by veins of silica in the form of quartz, chalcedony and opal; native gold is present, and silver can be found in a wide range of minerals (electrum, sulfosalts, cassiterite, galena, pyrite and chalcopyrite, among other minerals).

- High sulphidation (HS) ore: comes from deposits of the epithermal type of medium sulphidation, which is made up of quartz, carbonates and to a lesser extent $\mathrm{Au}$, and $\mathrm{Ag}$ sulphides and sulphosalts, in addition to $\mathrm{Pb}, \mathrm{Cu}$ and $\mathrm{Zn}$.

\subsubsection{Determination of Kinetic Parameters and Work Index}

The kinetic parameter $k$ was determined following the SIM methodology [14]. It is carried out in a Bond standard ball mill, with sample feed $700 \mathrm{~cm}^{3}$ (prepared according to the procedure presented in Figure 1). After PSD feed determination, a sole $5 \mathrm{~min}$ grinding run is performed, and the product PSD is obtained. This grinding time value was selected considering that grinding runs in the Bond standard test do not usually exceed 350 revolutions (5 min, at $70 \mathrm{rpm}$ ). For each size interval, $k$ is calculated (Equation (4)). 
Using Equation (2) for that set of $k$ and $x$ values, $C$ and $n$ for each ore are calculated, and an estimation of work index by CKM simulation, $w_{i, s}$, is performed [14].

The Bond work index $\left(w_{i}\right)$ was determined following BSM, the standard methodology developed by F. C. Bond [1]. The ball mill work index laboratory test is conducted by grinding an ore sample prepared to $100 \%$ passing $3.36 \mathrm{~mm}$ to product size in the range of $45-150 \mu \mathrm{m}$, thus determining the ball mill $w_{i}$. Several sources of variability, mainly due to a lack of procedure definition were identified by García et al. [24]. With the aim of reducing that variability, a detailed description of the test can be found in the proposal of the Global Mining Guidelines Group [25].

\section{Results and Discussion}

\subsection{Work Index Calculation and Estimation}

Table 1 shows the actual BSM $w_{i}$ values obtained versus the work index estimation by CKM simulation $\left(w_{i, s}\right)$. LS-CMLM1 and LS-CMVM1 samples were tested at a reference size $P_{100}=74 \mu \mathrm{m}$; estimated values by simulation differ less than $4 \%$. Meanwhile, HS-CCTUM1 sample was tested at $P_{100}=149 \mu \mathrm{m}$, and the estimation difference with the actual $w_{i}$ value was rounded by $6 \%$.

Table 1. Comparison between $w_{i}$ and $w_{i, s}$ for different metalliferous ores.

\begin{tabular}{ccccc}
\hline Sample & $\boldsymbol{P}_{\mathbf{1 0 0}}$ & $\begin{array}{c}\boldsymbol{w}_{\boldsymbol{i}} \\
{[\mathbf{k W h} / \mathbf{t}]}\end{array}$ & $\begin{array}{c}\boldsymbol{w}_{\boldsymbol{i , s}} \\
{[\mathbf{k W h} / \mathbf{t}]}\end{array}$ & Difference [\%] \\
\hline LS-CMLM1 & 74 & 26.59 & 27.63 & -3.91 \\
LS-CMVM1 & 74 & 25.17 & 24.56 & 2.42 \\
HS-CCTUM1 & 149 & 13.82 & 12.96 & 6.22 \\
\hline
\end{tabular}

Results of $w_{i}$ and $w_{i, s}$ calculations in the considered samples from previous research [9] complete the subsequent Tables 2 and 3.

Table 2. Grindability and kinetic parameters obtained experimentally.

\begin{tabular}{ccccccc}
\hline Sample & $\boldsymbol{P}_{\mathbf{1 0 0}}[\boldsymbol{\mu m}]$ & $\boldsymbol{F}_{\mathbf{8 0}}[\boldsymbol{\mu m}]$ & $\boldsymbol{P}_{\mathbf{8 0}}[\boldsymbol{\mu m}]$ & $\boldsymbol{w}_{\boldsymbol{i}}[\mathbf{k W h} / \mathbf{t}]$ & $\boldsymbol{g b} \boldsymbol{p}[\mathbf{g} / \mathbf{r e v}]$ & $\boldsymbol{k}\left(@ \boldsymbol{P}_{\mathbf{1 0 0}}\right)$ \\
\hline LS-CMLM1 & 74 & 1938 & 54 & 26.59 & 0.8038 & 0.03667 \\
LS-CMVM1 & 74 & 2053 & 53 & 25.17 & 0.6907 & 0.03656 \\
HS-CCTUM1 & 149 & 2469 & 96 & 13.82 & 1.3427 & 0.12543 \\
LS-CNM1 & 149 & 2508 & 113 & 21.17 & 1.0176 & 0.06539 \\
HS-CVM1 & 149 & 2284 & 115 & 16.31 & 1.4784 & 0.09132 \\
LS-CVM2 & 149 & 2432 & 116 & 17.57 & 1.2500 & 0.08693 \\
LS-CVM3 & 149 & 2333 & 114 & 19.08 & 1.1180 & 0.08143 \\
Quartz & 149 & 2572 & 117 & 15.27 & 1.5773 & 0.10141 \\
Quartz & 105 & 2552 & 83 & 19.89 & 1.1048 & 0.06492 \\
Feldspar & 149 & 1841 & 115 & 13.65 & 1.9112 & 0.13860 \\
Feldspar & 105 & 1676 & 81 & 16.16 & 1.3567 & 0.09183 \\
Limestone & 149 & 2407 & 108 & 10.88 & 2.2533 & 0.15128 \\
Calcite & 149 & 2497 & 112 & 6.93 & 3.9221 & 0.25711 \\
Cryst. limestone & 149 & 2062 & 112 & 8.46 & 3.3308 & 0.20919 \\
Cryst. limestone & 105 & 1926 & 79 & 10.91 & 2.2591 & 0.14956 \\
\hline
\end{tabular}


Table 3. Comparison $w_{i}$ versus $w_{i, e} 1$.

\begin{tabular}{|c|c|c|c|c|c|c|}
\hline Sample & $P_{100}[\mu \mathrm{m}]$ & $w_{i}[\mathrm{kWh} / \mathrm{t}]$ & $g b p[\mathrm{~g} / \mathrm{rev}]$ & $w_{i, e 1}[\mathrm{kWh} / \mathrm{t}]$ & $g b p_{e}[\mathrm{~g} / \mathrm{rev}]$ & Difference [\%] \\
\hline LS-CMLM1 & 74 & 26.59 & 0.8038 & 24.84 & 0.5869 & 6.59 \\
\hline LS-CMVM1 & 74 & 25.17 & 0.6907 & 24.48 & 0.5852 & 2.73 \\
\hline HS-CCTUM1 & 149 & 13.82 & 1.3427 & 11.23 & 1.8863 & 18.73 \\
\hline LS-CNM1 & 149 & 21.17 & 1.0176 & 20.77 & 1.0073 & 1.88 \\
\hline HS-CVM1 & 149 & 16.31 & 1.4784 & 16.37 & 1.3869 & -0.39 \\
\hline LS-CVM2 & 149 & 17.57 & 1.2500 & 16.97 & 1.3226 & 3.44 \\
\hline LS-CVM3 & 149 & 19.08 & 1.1180 & 17.77 & 1.2422 & 6.88 \\
\hline Quartz & 149 & 15.27 & 1.5773 & 15.09 & 1.5211 & 1.15 \\
\hline Quartz & 105 & 19.89 & 1.1048 & 18.65 & 1.0003 & 6.24 \\
\hline Feldspar & 149 & 13.65 & 1.9112 & 12.15 & 2.0790 & 11.00 \\
\hline Feldspar & 105 & 16.16 & 1.3567 & 14.74 & 1.3944 & 8.78 \\
\hline Limestone & 149 & 10.88 & 2.2533 & 10.44 & 2.2647 & 4.00 \\
\hline Calcite & 149 & 6.93 & 3.9221 & 6.94 & 3.8140 & -0.10 \\
\hline Cryst. limestone & 149 & 8.46 & 3.3308 & 8.42 & 3.1125 & 0.45 \\
\hline Cryst. limestone & 105 & 10.91 & 2.2591 & 9.66 & 2.2395 & 11.48 \\
\hline
\end{tabular}

\subsection{Relationships between Grindability and Kinetic Constant $k$}

Table 2 summarises the work indices determined by BSM and estimated by CKM with kinetic indices $k$ determined by the SIM procedure. The considered metalliferous ore samples came from the current research tests and the former research ones. Some non-metallic minerals from the former research are also included. All data are used to unveil the links between BSM parameters and those obtained by grinding kinetics (SIM).

After plotting $g b p$ (determined with the standard procedure) versus the kinetic parameter $k$ (calculated by the SIM methodology), as is shown in Figure 2, a linear estimation can be obtained (Equation (5)) with a correlation coefficient of $95.8 \%$.

$$
g b p=14.97 \cdot k
$$

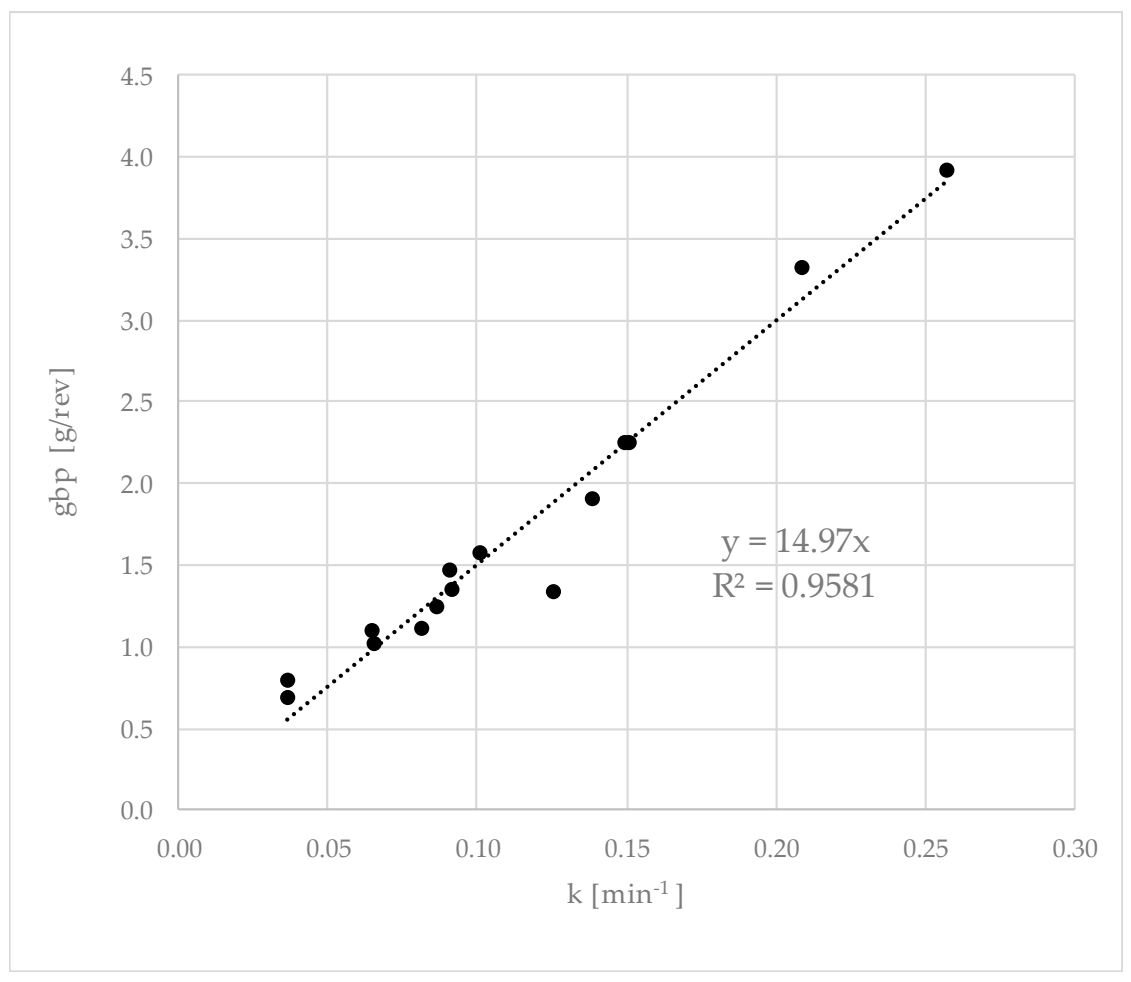

Figure 2. Plot $g b p$ (BSM) versus $k$ (SIM). 
According to the BSM procedure, $w_{i}$ can be calculated for each $P_{100}$ once $g b p, F_{80}$ and $P_{80}$ are known. A new work index estimation, $w_{i, e 1}$, can be suggested considering the $g b p$ estimated value $\left(g b p_{e}\right)$ in Equation (5), and $F_{80}$ and $P_{80}$ estimated by the SIM procedure, in each case. Table 3 shows the results obtained from this new estimation proposal, wherein work index differences are in general less than $10 \%$ for each ore. However, there are three values above $10 \%$ and one reaching $18 \%$.

Figure 3 depicts the relationship of $w_{i}$ versus $w_{i, e}$; a linear correlation (Equation (6)) can be plotted, with a correlation coefficient of $98.22 \%$.

$$
w_{i}=0.962 \cdot w_{i, e 1}-0.28
$$

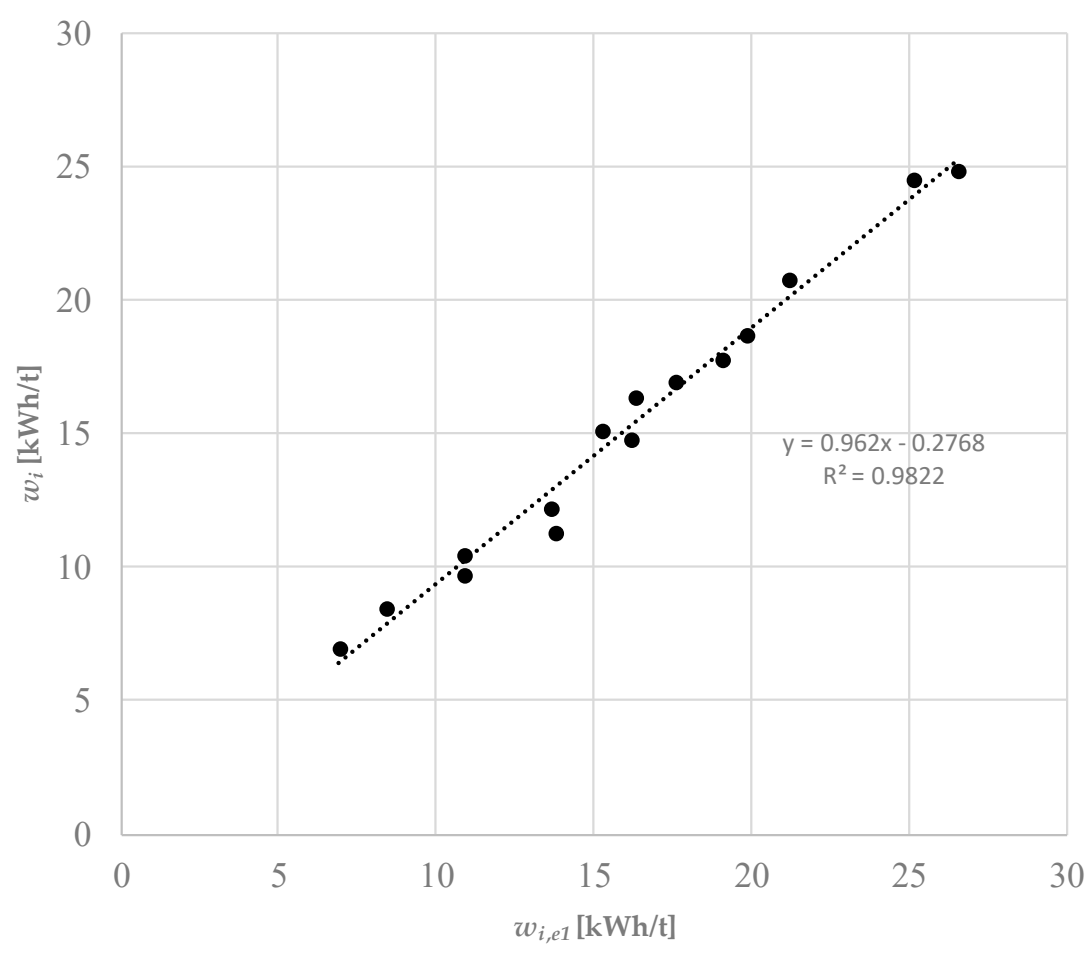

Figure 3. Linear correlation between $w_{i}$ and $w_{i, e 1}$.

\subsection{Linking the Work Index $w_{i}$ and the Kinetic Constant $k$}

As a consequence of the relationships evidenced in Equations (5) and (6), it can be inferred that there should be a correlation between the Bond work index and the kinetic constant $k$ at each monosize. Figure 4 depicts this relationship between $w_{i}$ and $k$ from the actual data gathered in Table 2, wherein a logarithmic correlation (Equation (7)) poses a correlation coefficient of $98.37 \%$.

$$
w_{i}=-10.07 \cdot \ln (k)-7.28
$$

Table 4 shows a comparison of actual work index values versus work index estimation using Equation (7); in all cases, differences are lower than 9\%. 


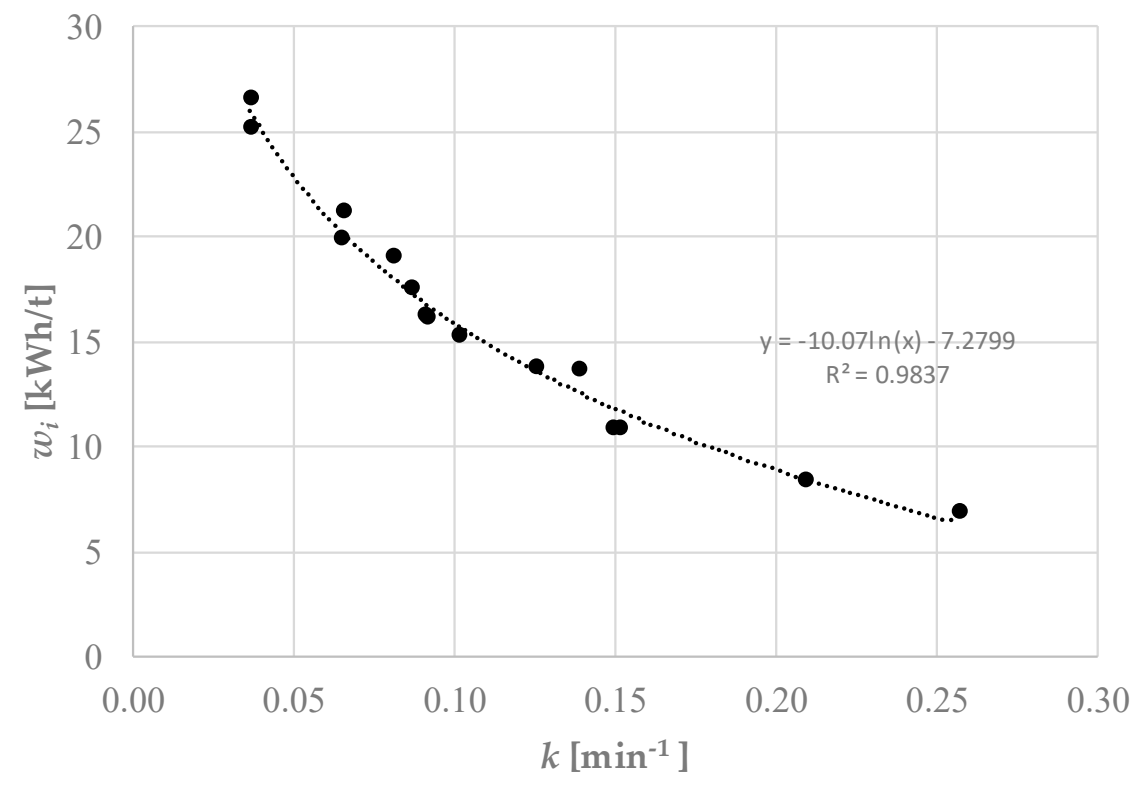

Figure 4. Logarithmic correlation $w_{i}$ versus $k$.

Table 4. Comparison between $w_{i}$ and work index estimation using Equation (7), $w_{i, e 2}$.

\begin{tabular}{cccccc}
\hline Sample & $\boldsymbol{P}_{\mathbf{1 0 0}}[\boldsymbol{\mu m}]$ & $\boldsymbol{w}_{\boldsymbol{i}}[\mathbf{k W h} / \mathbf{t}]$ & $\boldsymbol{k}\left[\mathbf{@ P}_{\mathbf{1 0 0}}\right]$ & $\boldsymbol{w}_{\boldsymbol{i , \boldsymbol { e }} \mathbf{2}}[\mathbf{k W h} \mathbf{t}]$ & Difference [\%] \\
\hline LS-CMLM1 & 74 & 26.59 & 0.03667 & 26.09 & 1.89 \\
LS-CMVM1 & 74 & 25.17 & 0.03656 & 26.12 & -3.77 \\
HS-CCTUM1 & 149 & 13.82 & 0.12543 & 13.67 & 1.10 \\
LS-CNM1 & 149 & 21.17 & 0.06539 & 20.25 & 4.36 \\
HS-CVM1 & 149 & 16.31 & 0.09132 & 16.87 & -3.45 \\
LS-CVM2 & 149 & 17.57 & 0.08693 & 17.37 & 1.13 \\
LS-CVM3 & 149 & 19.08 & 0.08143 & 18.03 & 5.50 \\
Quartz & 149 & 15.27 & 0.10141 & 15.81 & -3.57 \\
Quartz & 105 & 19.89 & 0.06492 & 20.32 & -2.16 \\
Feldspar & 149 & 13.65 & 0.13860 & 12.66 & 7.26 \\
Feldspar & 105 & 16.16 & 0.09183 & 16.82 & -4.06 \\
Limestone & 149 & 10.88 & 0.15128 & 11.78 & -8.23 \\
Calcite & 149 & 6.93 & 0.25711 & 6.42 & 7.38 \\
Cryst. limestone & 149 & 8.46 & 0.20919 & 8.50 & -0.49 \\
Cryst. limestone & 105 & 10.91 & 0.14956 & 11.89 & -8.99 \\
\hline
\end{tabular}

In Figure 5, the estimated work index using Equation (7) $w_{i, e}$ is plotted versus $w_{i}$, revealing the unexpected linear correlation shown in Equation (8), with a correlation coefficient of $98.37 \%$

$$
w_{i}=0.997 \cdot w_{i, e 2}-0.001
$$




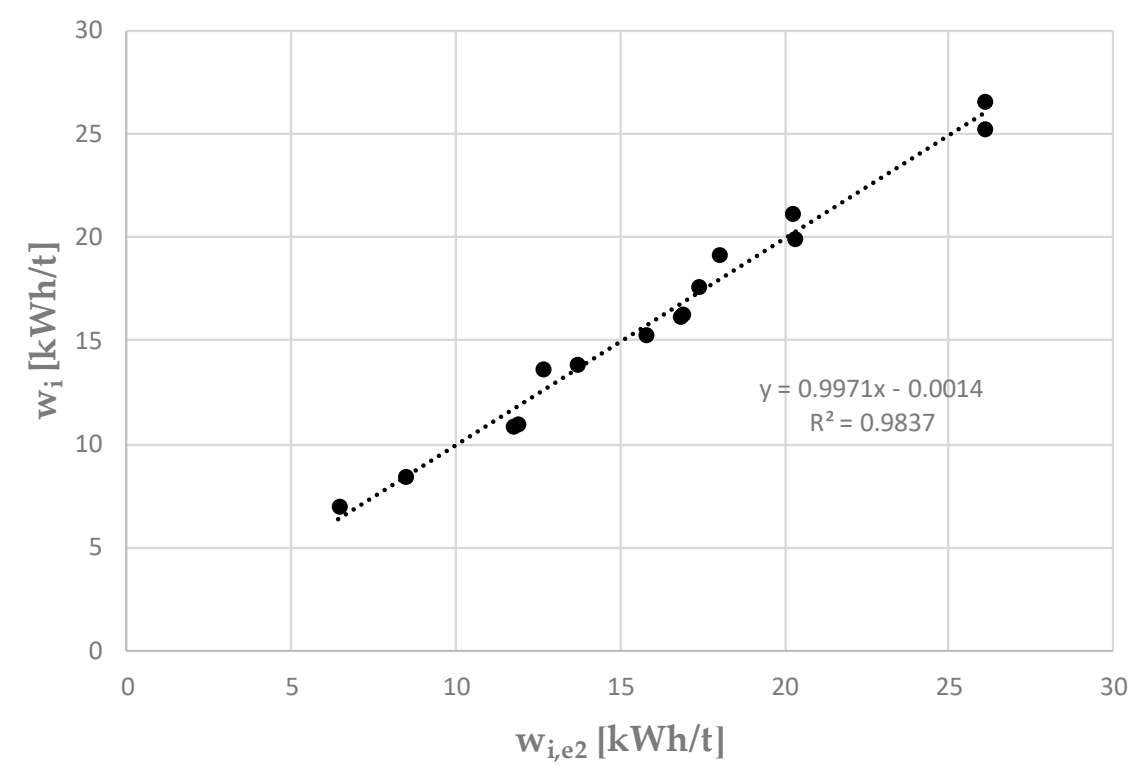

Figure 5. Linear correlation $w_{i}$ versus $w_{i, e 2}$.

\subsection{Discussion}

Table 1 presented the work index estimation by CKM simulation $\left(w_{i, s}\right)$ versus the actual $w_{i}$ values, in the case of three different samples. Results show deviations less than $6 \%$. This procedure saves laboratory time ( 8 to $2 \mathrm{~h}$, approximately) and reduces sample needs from $10 \mathrm{~kg}$ to less than $1.5 \mathrm{~kg}$.

Intending to get a more significant reduction, the research work focused on searching for a correlation between the $k$ kinetic parameter, determined by the SIM methodology developed by Ciribeni et al. [10], and the grindability index, gbp. As can be observed in Figure 2, a good linear correlation (Equation (5)) was obtained, opening the possibility of estimating $g b p$ from the $k$ value (which can be obtained in the laboratory more easily and quickly) and thus providing a new proposal of work index estimation, $w_{i, e}$.

In Table 3, the comparison between $w_{i}$ (Bond work index value obtained following the BSM) and $w_{i, e}$ showed differences, in general, lower than $9 \%$, being in some cases greater than $10 \%$, even reaching $18 \%$ in one specific case. This fact can raise the consideration that this methodology is a bit erratic.

On the other hand, the study of the relationship between $w_{i}$ and $k$ presents an adjustment to a logarithmic function with a correlation coefficient higher than $98 \%$, which is more than acceptable considering that this result was obtained adjusting data of fifteen actual $w_{i}$ determinations on different ores and with different $P_{100}$. The estimation of $w_{i}$ using Equation (7) posed differences lower than $9 \%$ in all cases and for all reference sizes. Moreover, in Table 4, it is observed that in the case of metalliferous ores, differences are below $5.50 \%$, with higher variability in the case of non-metalliferous ones. Amadi and Shahsavari [9] reported deviations lower than 7\%, and Aksani and Sönmez reported values lower than $4 \%$, using in both cases the CKM simulation-based methodology, that is, in the same order of magnitude.

According to results depicted in Figure 5, where the linear fitting (Equation (8)) casts a correlation coefficient higher than $98 \%$ with a slope very close to one and an almost zero intercept, it seems feasible and accurate enough to perform the work index estimation at a given $P_{100}$, just by knowing the kinetic parameter $k$ obtained at $P_{100}$ and by using Equation (7).

The combination of the SIM methodology [14] with the correlation of $k$ and $w_{i}$ provides a quick solution, with a minimum sample amount needed, in order to estimate the work index. An additional advantage is the reduction of procedures involving sample manipulation and quartering at the lab, which are usual sources of experimental error. 


\section{Conclusions}

From the results obtained in this research, the following conclusions can be highlighted:

- Once the CKM kinetic parameter $k$ for the given reference sieve $P_{100}$ was known, it was possible to estimate the BSM ball mill work index at that reference size, with differences lower than $9 \%$ with the Bond standard methodology.

- It was found that a linear fit yielded a correlation coefficient higher than $96 \%$ between $g b p$ and the kinetic parameter $k$ (Equation (5)). The line has slope fifteen and zero intercept. However, estimating $w_{i}$ by determining $g b p$ with Equation (5) and calculating $w_{i}$ with the Bond equation gives some erratic values.

- With fifteen different ore samples and for three different $P_{100}$, a logarithmic correlation $w_{i}$ versus $k$ was obtained (Equation (7)) with a correlation coefficient higher than $98 \%$. It can be suggested that the logarithmic function in Equation (7) could be a valuable tool as a quick alternative to Bond's standard test in the day-by-day grindability control.

- $\quad$ The comparison between $w_{i}$ and $w_{i, e 2}$ (Equation (8)) shows a linear fit whose slope is unity and the ordinate to the origin is negligible, with a correlation coefficient higher than $98 \%$.

- $\quad$ The use of $k$ versus $w_{i}$ correlation provides a quick solution, with a minimum sample amount need, in order to estimate the work index.

Author Contributions: Conceptualization, J.M.M.-A., A.L.C.-V. and V.C.; methodology, J.M.M.-A. and V.C.; software, V.C.; validation, V.C., R.B. and A.T.; formal analysis and investigation, V.C., R.B., A.T., M.P., E.A. and M.P.; resources, J.M.M.-A. and V.C.; writing-original draft preparation, V.C.; writing-review and editing, J.M.M.-A. and A.L.C.-V.; supervision, A.L.C.-V. All authors have read and agreed to the published version of the manuscript.

Funding: This research does not receive external funding.

Institutional Review Board Statement: Not applicable.

Informed Consent Statement: Not applicable.

Data Availability Statement: Not applicable.

Conflicts of Interest: The authors declare no conflict of interest.

\section{References}

1. Bond, F.C. Crushing and grinding calculations. Part I. Br. Chem. Eng. 1961, 6, 378-385.

2. Gutiérrez, L.; Sepúlveda, J. Dimensionamiento y Optimización de Plantas Concentradoras, Mediante Técnicas de Modelación Matemática; CIMM: Santiago, Chile, 1986.

3. Valerevich Lvov, V.; Sergeevich Chitalov, L. Comparison of the Different Ways of the Ball Bond Work Index Determining. Int. J. Mech. Eng. Technol. 2019, 10, 1180-1194. Available online: https:/ /ssrn.com/abstract=3452642 (accessed on 2 July 2021).

4. Nikolić, V.; Trumić, M. A new approach to the calculation of Bond work index for finer samples. Miner. Eng. 2021, 165, 106858. [CrossRef]

5. Josefin, Y.; Doll, A.G. Correction of Bond Ball Mill Work Index Test for Closing Mesh Sizes. Procemin-Geomet 2018. In Proceedings of the 14th International Mineral Processing Conference \& 5th International Seminar on Geometallurgy, Santiago, Chile, 28-30 November 2018; pp. 1-12.

6. Park, J.; Kim, K. Use of drilling performance to improve rock-breakage efficiencies: A part of mine-to-mill optimization studies in a hard-rock mine. Int. J. Min. Sci. Technol. 2020, 30, 179-188. [CrossRef]

7. Aksani, B.; Sönmez, B. Simulation of Bond grindability test by using cumulative based kinetic model. Miner. Eng. 2000, 13, 673-677. [CrossRef]

8. Menéndez-Aguado, J.M.; Dzioba, B.R.; Coello-Velazquez, A.L. Determination of work index in a common laboratory mill. Miner. Metall. Process. 2005, 22, 173-176. [CrossRef]

9. Ahmadi, R.; Shahsavari, S. Procedure for determination of ball Bond work index in the commercial operations. Miner. Eng. 2009, 22, 104-106. [CrossRef]

10. Mwanga, A.; Rosenkranz, J.; Lamberg, P. Testing of ore comminution behavior in the geometallurgical context: A review. Minerals 2015, 5, 276-297. [CrossRef]

11. Mwanga, A.; Rosenkranz, J.; Lamberg, P. Development and experimental validation of the Geometallugical Comminution test (GCT). Miner. Eng. 2017, 108, 109-114. [CrossRef] 
12. Heiskari, H.; Kurki, P.; Luukkanen, S.; Gonzalez, M.; Lehto, H.; Liipo, J. Evelopment of a comminution test method for small ore samples. Miner. Eng. 2019, 130, 5-11. [CrossRef]

13. Niitti, T. Rapid evaluation of grindability by a simple batch test. In Proceedings of the International Mineral Processing Congress Proceedings, Prague, Czech Republic, 1-6 June 1970; pp. 41-46.

14. Ciribeni, V.; Bertero, R.; Tello, A.; Puertas, M.; Avellá, E.; Paez, M.; Menéndez Aguado, J.M. Application of the Cumulative Kinetic Model in the Comminution of Critical Metal Ores. Metals 2020, 10, 925. [CrossRef]

15. Lewis, K.A.; Pearl, M.; Tucker, P. Computer Simulation of the Bond Grindability Test. Miner. Eng. 1990, 3, 199-206. [CrossRef]

16. Silva, M.; Casali, A. Modelling SAG Milling Power and Specific Energy Consumption Including the Feed Percentage of Intermediate Size Particles. Miner. Eng. 2015, 70, 156-161. [CrossRef]

17. Deniz, V. Relationships Between Bond's Grindability (Gbg) and Breakage Parameters of Grinding Kinetic on Limestone. Powder Technol. 2004, 139, 208-213. [CrossRef]

18. Austin, L.G.; Klimpel, R.R.; Luckie, P.T. Process Engineering of Size Reduction: Ball Milling; SME-AIME: New York, NY, USA, 1984.

19. Bilgili, E.; Scarlett, B. Population balance modeling of nonlinear effects in milling processes. Powder Technol. 2005, $153,59-71$. [CrossRef]

20. Petrakis, E.; Komnitsas, K. Development of a Non-linear Framework for the Prediction of the Particle Size Distribution of the Grinding Products. Min. Metall. Explor. 2021, 38, 1253-1266.

21. Laplante, A.R.; Finch, J.A.; del Villar, R. Simplification of Grinding Equation for Plant Simulation. Trans. Inst. Min. Metall. (Sect. C) 1987,96, C108-C112.

22. Loveday, B.K. An analysis of comminution kinetics in terms of size distribution parameters. J. S. Afr. Inst. Min. Metall. 1967, 68, 111-131.

23. Ersayin, S.; Sönmez, B.; Ergün, L.; Aksani, B.; Erkal, F. Simulation of the Grinding Circuit at Gümüsköy Silver Plant, Turkey. Trans. Inst. Min. Metall. (Sect. C) 1993, 102, C32-C38.

24. García, G.G.; Oliva, J.; Guasch, E.; Anticoi, H.; Coello-Velázquez, A.L.; Menéndez-Aguado, J.M. Variability Study of Bond Work Index and Grindability Index on Various Critical Metal Ores. Metals 2021, 11, 970. [CrossRef]

25. GMG—Global Mining Guidelines Group. Determining the Bond Efficiency of Industrial Grinding Circuits. 2016. Available online: https://gmggroup.org/wp-content/uploads/2016/02/Guidelines_Bond-Efficiency-REV-2018.pdf (accessed on 1 July 2021). 